\title{
Cellular Uptake Mediated by Cyclic Oligochalcogenides
}

\author{
Rémi Martinent $\S^{\star}$, Quentin Laurent, Naomi Sakai, and Stefan Matile* \\ §SCS-DSM Award for best poster presentation in Medicinal Chemistry
}

\begin{abstract}
Cellular uptake is one of the central challenges in chemical biology and beyond. With the objective to find conceptually innovative ways to enter into cells, cyclic oligochalcogenides (COCs) are emerging as powerful tools. Increasing ring tension is shown to maximize speed and selectivity of dynamic covalent exchange chemistry on the way into cells. However, simple dynamic covalent attachment immobilizes the transporters on membrane proteins, resulting in endosomal capture. To move across the membrane into the cytosol, dynamic covalent COC opening has to produce high acidity chalcogenols that remain deprotonated in neutral water and, according to the present working hypothesis, initiate COC walking along disulfide tracks in membrane proteins, across the bilayer and into the cytosol. Compatibility of diselenolanes, the current 'lord of the rings', with the delivery of larger substrates of biological relevance is currently under investigation.
\end{abstract}

Keywords: Cellular uptake · Dynamic covalent chemistry $\cdot$ Molecular walkers $\cdot$ Reactive intermediates

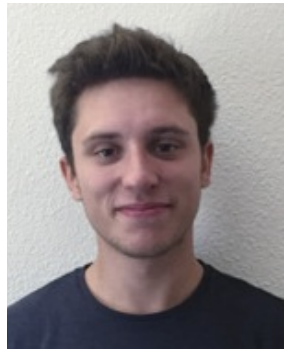

Rémi Martinent obtained his MSc in organic chemistry from the Université Claude Bernard in Lyon, France, as well as his chemical engineer degree from $\mathrm{CPE}$ Lyon in 2017. Before graduating, he did a 12-months internship on the synthesis of kinase inhibitors at Origenis $\mathrm{GmbH}$, Munich, Germany. In 2017, he carried out his master thesis project with Dr. E. Fontaine from Sanofi Aventis in Lyon, France, as a medicinal chemist and moved to Geneva, Switzerland, to begin a $\mathrm{PhD}$ under the supervision of Professor Stefan Matile, where he is working on cellular uptake.

The delivery of substrates of free choice - drugs, probes, peptides, proteins, oligonucleotides, vesicles, nanoparticles - into cells is a central challenge in the life sciences. The relevance of this topic in the NCCRs Chemical Biology ${ }^{[1]}$ and Molecular Systems Engineering ${ }^{[2]}$ illustrates the general nature of the challenge very well. Its persistence despite massive efforts worldwide calls for a shift of attention toward conceptually innovative approaches to, hopefully, identify new ways to enter into cells. Along this line, we took note that the unique properties of the recently introduced cell-penetrating poly(disulfide)s (CPDs $)^{[3-9]}$ might originate not from repulsion-driven ion pairing associated with cell-penetrating peptides (CPPs ${ }^{[10,11]}$ but from dynamic covalent disulfide exchange chemistry. ${ }^{[4,12-16]}$ Casual observations that dynamic covalent dichalcogenide exchange chemistry might mediate cellular uptake can be traced far back in the literature. ${ }^{[17]}$ The first among more explicit studies ${ }^{[17-22]}$ arguably came from the Sagan group in Paris. ${ }^{[18]}$ As soon as we understood that CPDs might function this way, we knew that we have to take a closer look at cyclic oligochalcogenides (COCs) to elaborate on speed, selectivity and even the nature of dynamic covalent exchange chemistry on the way into a cell (Fig. 1). For this purpose, COCs and controls 1-7

${ }^{\star}$ Correspondence: R. Martinent, Prof. S. Matile

E-mail: Remi.Martinent@unige.ch, Stefan.Matile@unige.ch

Department of Organic Chemistry, University of Geneva, Geneva, Switzerland have been attached to a fluorophore. ${ }^{[23-25]}$ According to flow cytometry, cellular uptake increased from left to right in Fig. 1. Up to epidithiodiketopiperazine (ETP) $\mathbf{5}$, this trend can be understood with ring tension. In relaxed acyclic disulfides, the CSSC dihedral angle is $90^{\circ}$ to minimize lone pair repulsion and maximize hyperconjugation. ${ }^{[26,27]}$ Activation of acyclic disulfides with good leaving groups as in $\mathbf{1}$ does much to improve cellular uptake. ${ }^{[23]}$ The same is true for minimal ring tension present in DTT 2 with CSSC $\sim 60^{\circ}$. With a further increase in tension in lipoic acid 3 and asparagusic acid (AspA) 4, an increasing uptake can be observed.[23] At maximal ring tension in ETP 5 with $\mathrm{CSSC} \sim 0^{\circ}$ cellular uptake further increases. ${ }^{[24]}$ Moving from sulfur to selenium, ${ }^{[28-36]}$ relaxed acyclic diselenides $\mathbf{6}$ are already more active than disulfides $\mathbf{5}$ at maximal tension. ${ }^{[25]}$ Moreover, the application of ring tension in diselenolane (DSL) 7 did not further increase activity dramatically. Ring tension in diselenolanes in general is less important because of the longer selenium-selenium bonds that reduce lone-pair repulsion and hyperconjugation. Comparison of the resulting CSeSeC $\sim 0^{\circ}$ of diselenolane 7 compared to the $\mathrm{CSSC}=35^{\circ}$ of thiolane 2 illustrates this difference in ring tension very well.

Fluorescence microscopy images revealed that dithiolane 4 and acyclic diselenide $\mathbf{6}$ are mostly trapped in endosomes, whereas ETP $\mathbf{5}$ and diselenolane $\mathbf{7}$ avoid endosomal capture and enter into cytosol and nucleus (Fig. 2). Passing through thiol exchange affinity columns, significant retention and release only upon addition of DTT to the mobile phase was found for $\mathbf{4}$ and $\mathbf{6}$ but not for 5 and 7 (Fig. 2, peak indicated by *). The coincidence of endosomal capture and retention on thiol exchange affinity columns supported that $\mathbf{4}$ and $\mathbf{6}$ exchange with thiols on the cell surface, where they remain immobilized and undergo endocytosis. In clear contrast, the efficient entry of ETP 5 and DSL 7 into cytosol and nucleus coincides with negligible retention on affinity columns (Fig. 2). This suggested that they either do not exchange with thiols on the way into cells, or dynamic covalent exchange is reversible and repeated several times to walk ${ }^{[37-39]}$ along thiol or, more likely, disulfide tracks into the cytosol. Most importantly, the chalcogenols obtained by thiol-mediated opening of ETP $\mathbf{5}$ and DSL 7 both have a $\mathrm{p} K_{\mathrm{a}}<7$ and thus exist as reactive chalcogenates in neutral water. The presence of a nearby reactive chalcogenate is essential for COC mobility. 
Fig. 1. Uptake efficiency of fluorescein-labeled dichalcogenides 1-7 into HeLa cells increases from left to right, with selected CXXC dihedral angles $(\mathrm{X}=\mathrm{S}$ or $\mathrm{Se})$.

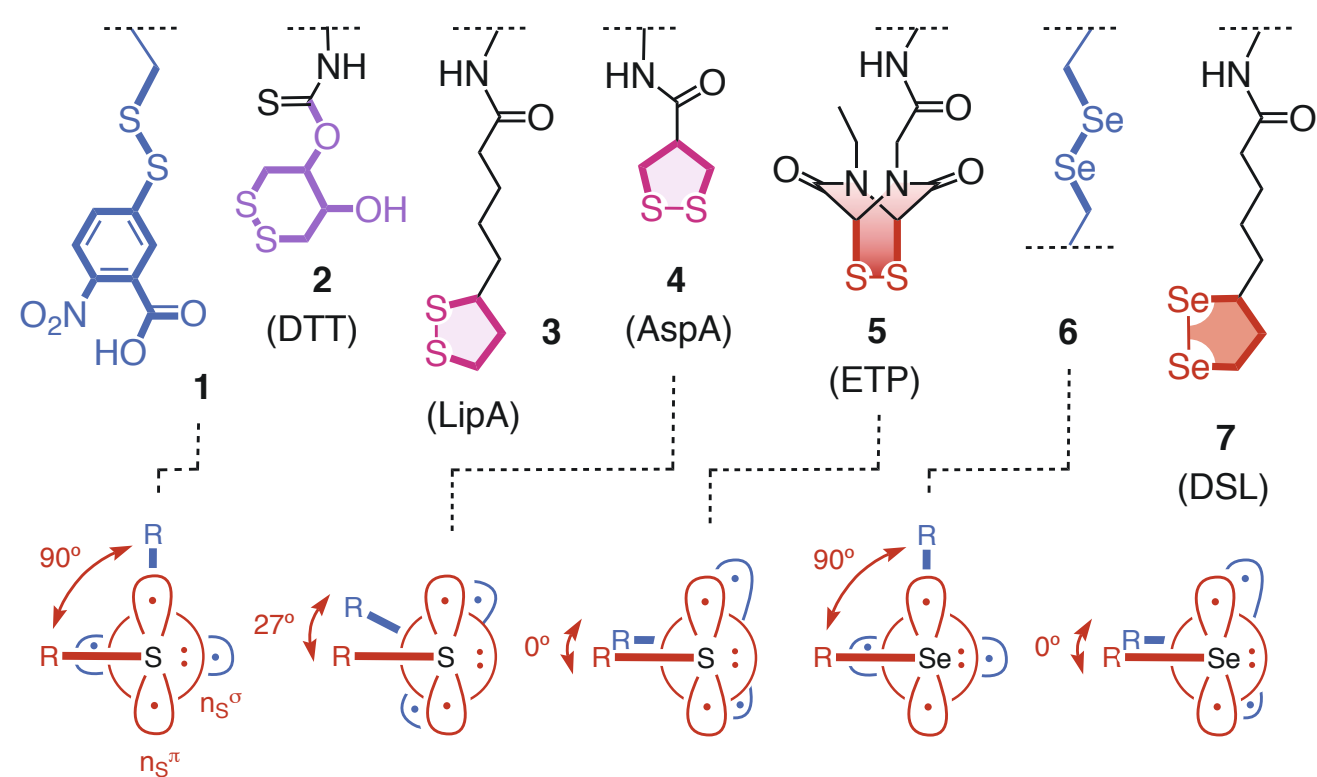

Exchange of ETP 5 with thiols was easily detectable by NMR spectroscopy because ring opening is favored.[24] Exchange of DSL 7 with thiols was more difficult to detect because these COCs prefer to stay closed as selenophilicity overcompensates ring tension. ${ }^{[25]}$ First indications that DSL 7 exchanges with thiols was obtained from the catalysis of DTT 8 oxidation into disulfide 9 (Fig. 3). ${ }^{[25]}$ Spontaneous oxidation of diselenol 10 with air recycles catalyst 7 . This observation was important because it also indicated that intramolecular ring closure with the thiol in intermediate $\mathbf{1 1}$ can compete with ring closure with the selenol.

More detailed insights into thiol-mediated ring opening of DSL 7 were obtained by trapping experiments at low temperature (Fig. 4). ${ }^{[40]}$ Opening with thiols 12 was found to occur on the secondary selenium atom. The secondary selenosulfide $\mathbf{1 3}$ then rearranges by up to $\sim 40 \%$ only into the primary constitutional isomer 14. This formal first step of a DSL walker occurs in $4 \mathrm{~ms}$. Both reactive intermediates were trapped with iodoacetamide $\mathbf{1 5}$. The resulting isomers $\mathbf{1 6}$ and $\mathbf{1 7}$ convert during workup into 'tail-tail',
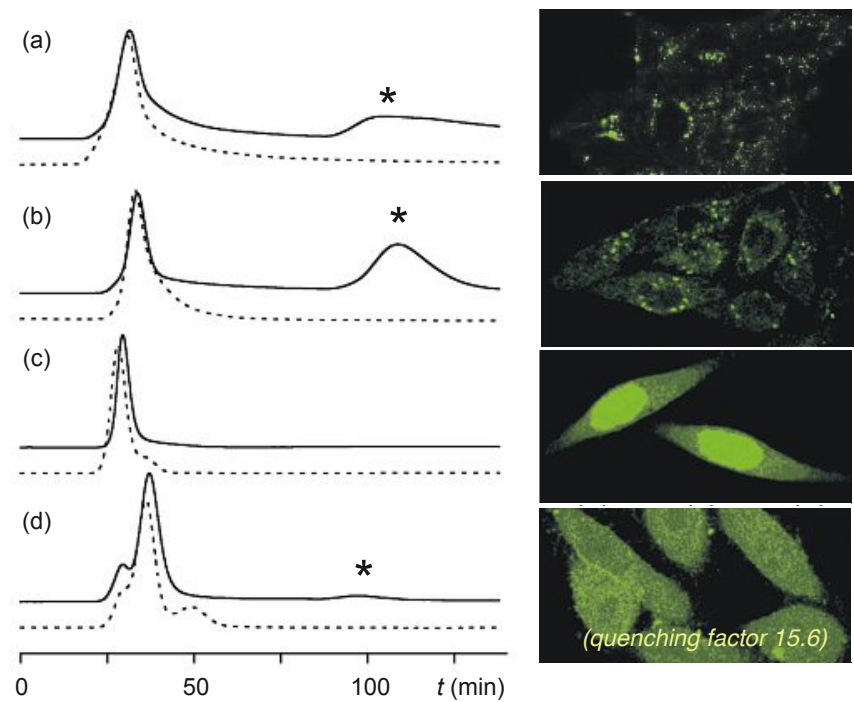

Fig. 2. Thiol-exchange affinity column chromatograms with a $0-50 \mathrm{mM}$ DTT gradient at $t=60-70 \mathrm{~min}$ (solid) and constant $50 \mathrm{mM}$ DTT from $t$ $=0$ (dashed, left), and fluorescence microscopy images of HeLa Kyoto cells (right) after addition of (a) 6, (b) AspA 4, (c) ETP 5 and (d) DSL 7. Images are not corrected for quenching by COCs, particularly pronounced with 7 (factor 15.6). *Elution after addition of DTT demonstrates immobilization by thiol-mediated dynamic covalent exchange. Adapted from ref. [24] with permission, copyright RSC 2018. 'head-tail' and 'head-head' diselenides 18-18, 18-19 and 19-19, which were readily discriminated and quantified by NMR spectroscopy. This direct experimental evidence for mobility supports a working hypothesis with DSL as a molecular walker ${ }^{[37-39]}$ that moves along disulfide tracks into cells, possibly causing temporary local membrane protein denaturation ${ }^{[33-35]}$ next to the adaptive, non-leaky and self-healing micellar pores known from CPPs and CPDs ${ }^{[10]}$ (Fig. 5).

Application of the same analysis to lipoic acid $\mathbf{3}$ gave almost identical results, i.e. opening on the secondary sulfur followed by fast, partial rearrangement of secondary 20 into primary 21. ${ }^{[40]}$ The main difference is the poor acidity of the released thiol. Contrary to selenols 13 and $\mathbf{1 4}$ with $\mathrm{p} K_{\mathrm{a}}<7$, thiols 20 and $\mathbf{2 1}$ with $\mathrm{p} K_{\mathrm{a}}>7$ are protonated in neutral water. Interestingly, indications of existing but poor mobility can be seen in fluorescence images of AspA 4 added to HeLa cells (Fig. 2b, faint diffuse emission around strong punctate emission from endosomes ${ }^{[23]}$ ). This background emission from cytosolic delivery is much less present in acyclic diselenides $\mathbf{6}$, unable to walk after losing one leg during the first step (Fig. 2a).

With these intriguing mechanistic insights in hand, the big question was if COC-mediated uptake would also work with larger substrates of biological relevance. A DSL tag in scale next to a streptavidin tetramer looks as out-of-proportion as the ant carrying the elephant (Fig. 6). The compatibility of COC-mediated uptake is currently being addressed with a broad screening of substrates of

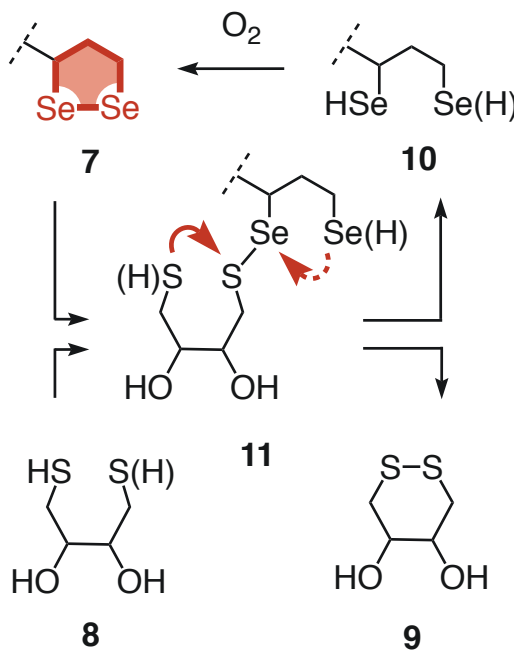

Fig. 3. The oxidation of DTT 8 is accelerated by DSL 7. 


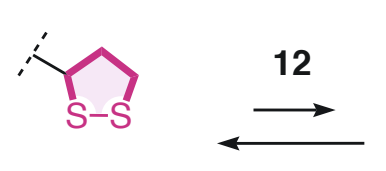

3

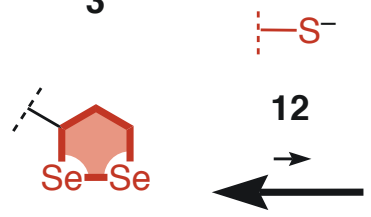

7<smiles>CCCC(C)CSS</smiles>

20 $t_{50}=7 \mathrm{~ms}$

$\mathrm{p} K_{\mathrm{a}} \sim 8$

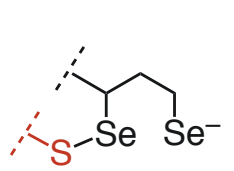

13

$$
\mathrm{p} K_{\mathrm{a}} \sim 5
$$
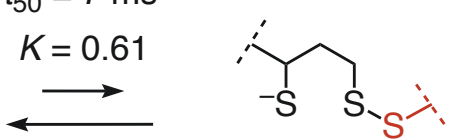

21

$t_{50}=4 \mathrm{~ms}$

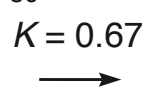

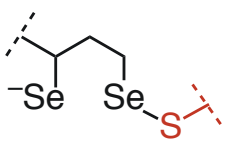

14

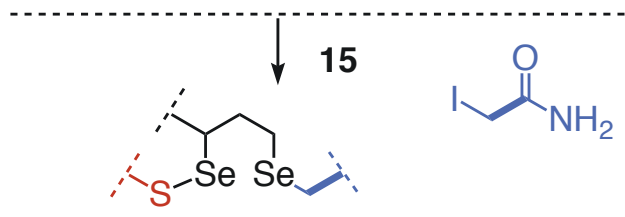

16
Fig. 4. Trapping of reactive intermediates resulting from the opening of DSL 7 with thiol 12 under basic conditions reveals selectivity for 13 , which then partially rearranges into 14. Almost the same occurs with lipoic acid $\mathbf{3}$, with the main difference that the obtained thiolate is protonated in neutral water.

Fig. 5. Working hypothesis for the mode of action of DSL-mediated cellular uptake, with dynamic covalent exchange cascades to let COC 7 walk along transmembrane disulfide tracks in membrane proteins, across the membrane for release into the cytosol.

relevance in the NCCR communities. ${ }^{[1,2]}$ Examples include proteincovered quantum dots, ${ }^{[7]}$ artificial metalloenzymes uncaging fluorescent probes, ${ }^{[8]}$ actin-targeting bicyclopeptides, mRNA targeting PNAs and antibiotics. The first positive results for the most promising DSL-mediated uptake have been reported recently. ${ }^{[41]}$

\section{Acknowledgements}

Rémi Martinent is grateful to the Swiss Chemical Society and DSM for the best poster award in Medicinal Chemistry and Chemical Biology. We thank all coworkers and collaborators for their contributions to this research, and the University of Geneva, the Swiss National Centre of Competence in Research (NCCR) Chemical Biology, the NCCR Molecular Systems Engineering and the Swiss NSF for financial support.

Received: January 28, 2019
Fig. 6. The ant and the elephant: In-scale model of a streptavidin tetramer carried by a diselenolane. Adapted from ref. [8] with permission, copyright Springer-Nature 2018, and from ref. [25] with permission, copyright RSC 2018. 
[1] https://nccr-chembio.ch

[2] http://www.nccr-mse.ch/en/

[3] E.-K. Bang, G. Gasparini, G. Molinard, A. Roux, N. Sakai, S. Matile, J. Am. Chem. Soc. 2013, 135, 2088

[4] G. Gasparini, E.-K. Bang, G. Molinard, D. V. Tulumello, S. Ward, S. O. Kelley, A. Roux, N. Sakai, S. Matile, J. Am. Chem. Soc. 2014, 136, 6069.

[5] P. Morelli, S. Matile, Helv. Chim. Acta 2017, 100, e1600370.

[6] P. Morelli, E. Bartolami, N. Sakai, S. Matile, Helv. Chim. Acta 2018, 101, e1700266.

[7] E. Derivery, E. Bartolami, S. Matile, M. Gonzalez-Gaitan, J. Am. Chem. Soc 2017, 139, 10172

[8] Y. Okamoto, R. Kojima, F. Schwizer, E. Bartolami, T. Heinisch, S. Matile M. Fussenegger, T. R. Ward, Nat. Commun. 2018, 9, 1943.

[9] S. Du, S. S. Liew, L. Li, S. Q. Yao, J. Am. Chem. Soc. 2018, 140, 15986.

[10] N. Chuard, K. Fujisawa, P. Morelli, J. Saarbach, N. Winssinger, P. Metrangolo, G. Resnati, N. Sakai, S. Matile, J. Am. Chem. Soc. 2016, 138, 11264.

[11] M. Grogg, D. Hilvert, M. Ebert, A. Beck, D. Seebach, F. Kurth, P. Dittrich, C. Sparr, S. Wittlin, M. Rottmann, P. Mäser, Helv. Chim. Acta 2018, 101, e18000112.

[12] J. Stefely, M. A. Markowitz, S. L. Regen, J. Am. Chem. Soc. 1988, 110, 7463.

[13] H. Y. Au-Yeung, F. B. L. Cougnon, S. Otto, G. D. Pantoş, J. K. M. Sanders, Chem. Sci. 2010, 1, 567.

[14] M. Lista, J. Areephong, N. Sakai, S. Matile, J. Am. Chem. Soc. 2011, 133, 15228.

[15] H. Hayashi, A. Sobczuk, A. Bolag, N. Sakai, S. Matile, Chem. Sci. 2014, 5, 4610.

[16] X. Zhang, R. M. Waymouth, J. Am. Chem. Soc. 2017, 139, 3822.

[17] E. P. Feener, W. C. Shen and H. J. P. Ryser, J. Biol. Chem. 1990, 265, 18780.

[18] S. Aubry, F. Burlina, E. Dupont, D. Delaroche, A. Juliot, S. Laveille, G. Chassaing, S. Sagan, FASEB J. 2009, 23, 2956.

[19] A. G. Torres, M. J. Gait, Trends Biotechnol. 2012, 30, 185.

[20] X. Meng, T. Li, Y. Zhao, C. Wu, ACS Chem. Biol. 2018, 13, 3078
[21] L. Brülisauer, N. Kathriner, M. Prenrecaj, M. A. Gauthier, J.-C. Leroux, Angew. Chem. Int. Ed. 2012, 51, 12454.

[22] D. Oupický, J. Li, Macromol. Biosci. 2014, 14, 908.

[23] G. Gasparini, G. Sargsyan, E.-K. Bang, E.-K.; Sakai, N.; Matile, S. Angew. Chem. Int. Ed. 2015, 54, 7328.

[24] L. Zong, E. Bartolami, D. Abegg, A. Adibekian, N. Sakai, S. Matile, ACS Cent. Sci. 2017, 3, 449.

[25] N. Chuard, A. I. Poblador-Bahamonde, L. Zong, E. Bartolami, J. Hiltebrandt, W. Weigand, N. Sakai, S. Matile, Chem. Sci. 2018, 9, 1860.

[26] A. D. Clauss, S. F. Nelsen, M. Ayoub, J. W. Moore, C. R. Landis, F. Weinhold, Chem. Educ. Res. Pract. 2014, 15, 417.

[27] C. P. Hiberty, B. Braïda, Angew. Chem. Int. Ed. 2018, 57, 5994.

[28] D. Steinmann, T. Nauser, W. H. Koppenol, J. Org. Chem. 2010, 75, 6696.

[29] B. Rasmussen, A. Sorensen, H. Gotfredsen. M. Pittelkow, Chem. Commun. 2014, 50, 3716

[30] C. C. Tjin, K. D. Otley, T. D. Baguley, P. Kurup, J. Xu, A. C. Nairn, P. J. Lombroso, J. A. Ellman, ACS Cent. Sci. 2017, 3, 1322.

[31] H. Xu, W. Cao, X. Zhang, Acc. Chem. Res. 2013, 46, 1647.

[32] S. Benz, C. Besnard, S. Matile, Helv. Chim. Acta 2018, 101, e1800075.

[33] N. Metanis, D. Hilvert, Chem. Sci. 2015, 6, 322.

[34] J. Beld, K. Woycechowsky, D. Hilvert, ACS Chem. Biol. 2010, 5, 177.

[35] S. Shimodaira, Y. Asano, K. Arai, M. Iwaoka, Biochemistry 2017, 56, 5644.

[36] J. C. Lukesh, B. VanVeller, R. T. Raines, Angew. Chem. Int. Ed. 2013, 52, 12901.

[37] H. D. Winkler, D. P. Weimann, A. Springer, C. A. Schalley, Angew. Chem Int. Ed. 2009, 48, 7246

[38] M. J. Barrell, A. G. Campaña, M. von Delius, E. M. Geertsema, D. A. Leigh, Angew. Chem. Int. Ed. 2011, 50, 285.

[39] J.-S. Shin, N. A. Pierce, J. Am. Chem. Soc. 2004, 126, 10834.

[40] Q. Laurent, N. Sakai, S. Matile, Helv. Chim. Acta 2019, 102, e1800209.

[41] E. Bartolami, D. Basagiannis, L. Zong, R. Martinent, Y. Okamoto, Q. Laurent, T. R. Ward, M. Gonzalez-Gaitan, N. Sakai, S. Matile, Chem. Eur $J .$, in press. 